\title{
PENGARUH LATIHAN MARATON JARAK BERTAHAP TERHADAP TINGKAT KESEGARAN JASMANI PESERTA DIDIK KEGIATAN EKSTRAKURIKULER KARATEDO SEKOLAH MENENGAH KEJURUAN PERSATUAN GURU REPUBLIK INDONESIA TANJUNG RAJA
}

\author{
Syarifuddin $^{1}$, M. Haris Satria ${ }^{2}$, Arif Hidayat ${ }^{3}$ \\ Universitas Bina Darma \\ syarifuddin343434@gmail.com¹, haris@binadarma.ac.id², arif.hidayat@binadarma.ac.id ${ }^{3}$
}

\begin{abstract}
ABSTRAK
Masalah dalam penelitian ini adalah adakah pengaruh latihan maraton jarak bertahap terhadap tingkat kesegaran jasmani siswa. Sedangkan tujuan penelitian untuk mengetahui adakah pengaruh latihan maraton jarak bertahap terhadap tingkat kesegaran jasmani siswa. Metode penelitian ini adalah penelitian kuantitatif dengan rancangan eksperimen one design group pretest-posttest. Populasi dalam penelitian ini adalah siswa putra ekstrakurikuler karatedo di SMK PGRI Tanjung Raja dengan jumlah populasi sebanyak 32 orang, sedangkan sampel diambil sama dengan jumlah populasi. Pengumpulan data menggunakan Tes Tingkat Kesegaran Jasmani, yang meliputi: lari 60 meter, gantung angkat tubuh, baring duduk, loncat tegak dan lari 1200 meter. Data yang diperoleh dianalisis menggunakan statistika uji-t. Hasil penelitian dan pembahasan menyatakan bahwa latihan maraton jarak bertahap berpengaruh secara signifikan terhadap tingkat kesegaran jasmani siswa putra ekstrakurikuler karatedo SMK PGRI Tanjung Raja.
\end{abstract}

Kata kunci: Latihan maraton jarak bertahap, tingkat kesegaran jasmani, ekstrakurikuler.

\section{THE EFFECT OF MARATON TRAINING TOWARDS THE STAGE OF JASMANI \\ RELIGIOUS LEVEL OF PARTICIPANTS IN EDUCATION EXTRACURRICULAR ACTIVITIES KARATEDO SCHOOL INTERMEDIATING TEACHERS 'COMMITMENT OF THE REPUBLIC OF INDONESIA \\ TANJUNG KING}

\begin{abstract}
The problem in this research is the influence of exercise does the maraton distance gradually towards the level of physical freshness students. Whereas the purpose of the study is to know the influence of the distance of the maraton exercises staged against physical freshness level students. The method of this research is quantitative research with the design of experiments one group pretest-posttest disign. The population in this research is the son of extracurricular student karatedo in SMK PGRI Tanjung Raja with a total population of 32 people, whereas samples taken the same amount of the population. Data collection using the test level of physical freshness, which includes: 60 meter dash, suspension lift, body baring sit, jump and run upright, 1200 metres. The data obtained were analyzed using t-test statistics. Research results and discussion stated that exercises maraton distance gradually effect significantly to levels of physical freshness students extracurricular son karatedo SMK PGRI Tanjung Raja.
\end{abstract}

Keywords: Gradual distance marathon training, physical fitness level, extracuriculer.

Dipublikasikan Oleh :

UPT Publikasi dan Pengelolaan Jurnal

Universitas Islam Kalimantan Muhammad Arsyad Al-Banjari Banjarmasin 


\section{PENDAHULUAN}

Kesegaran jasmani seseorang berkaitan dengan kesehatan terlihat ketika melakukan suatu aktivitas fisik tanpa mengalami kelelahan yang berlebihan, dan memiliki risiko lebih rendah untuk mengalami penyakit kronik lebih awal. Hal ini sejalan dengan pendapat Sumaryoto dan Nopembri (2016:145) yang mengatakan bahwa kesegaran jasmani adalah kemampuan seseorang dalam melakukan aktivitas keseharian tanpa mengalami kelelahan yang berarti, dan masih mempunyai cadangan sisa tenaga untuk melakukan aktivitas yang lain. Aktivitas kesegaran jasmani merupakan hal penting untuk meningkatan kualitas fisik, karena dengan kesegaran jasmani tentunya seseorang akan dapat beraktivitas secara maksimal dalam kehidupan sehari-hari sehingga dapat meningkatkan kualitas hidupnya. Terdapat banyak pilihan aktivitas jasmani yang dapat dilakukan oleh seseorang agar dapat meningkatkan kualitas hidupnya agar senantiasa sehat dan bugar, antara lain dengan berjalan santai, lari, jogging, besepeda, dan senam, tetapi kebanyakan dari mereka melakukan aktivitas tersebut belum mengetahui manfaatnya. Mereka melakukan olahraga maupun permainan hanya untuk memperoleh kesenangan, sehingga dalam melakukan kegiatan tersebut tidak sesuai dengan program latihan yang sesuai.

Manfaat yang dapat diperoleh dalam melakukan kegiatan olahraga, disamping menjadikan tubuh yang bugar akan dapat meningkatkan kemampuan jantung dan paru-paru, memperkuat sendi dan otot, menurunkan tekanan darah, mengurangi lemak, memperbaiki bentuk tubuh serta banyak hal yang tentunya sangat bermanfaat untuk tubuh. Masyarakat saat itu menyaradari akan kesehatan, banyak diantaranya berupaya meningkatkan kesehatan dengan melakukan rutinitas berolahraga, agar merasa sehat dan lebih semangat dalam hidupnya. Untuk itu agar peningkatan kualitas fisik masyarakat dapat terwujud dengan baik perlu ada komitmen dan dukungan dari pemerintah agar dapat mewujudkan kualitas fisik masyarakat yang sehat dan maju sehingga dapat mewujudkan manusia yang energik atau produktif yang mana hal ini merupakan modal utama dalam strategi dasar era pembangunan dan modernisasi serta akselerasi.

Pada dasarnya pembinaan kesegaran jasmani dapat dilakukan dengan berbagai macam latihan jasmani atau olahraga, dan semua jenis latihan dan olahraga tersebut dapat digunakan untuk meningkatkan kesegaran jasmani Kesegaran jasmani merupakan kebutuhan yang sangat penting bagi semua orang, agar senantiasa dapat menyelesaikan tugas mereka sehari-hari dengan baik dan maksimal. Terlebih lagi untuk peserta didik di sekolah, tentunya kesegaran jasmani sangatlah penting agar peserta didik senantiasa sehat, aktif dan ceria sehingga selalu bersemangat dalam belajar baik di luar kelas maupun di dalam kelas, sehingga harapannya dengan kondisi ini peserta didik akan memiliki konsentrasi yang baik saat menerima pelajaran di sekolah.

Namun kenyataannya, pada saat ini peserta didik senantiasa lebih tertarik oleh permainan yang tidak melibatkan aktivitas fisik secara keseluruhan, seperti permainan game, facebook maupun bermain internet hingga berjam-jam daripada beraktivitas dengan teman temannya di luar rumah. Ketika berangkat ke sekolahpun peserta didik terbiasa diantar oleh orangtuanya meskipun jarak rumah mereka tidak begitu jauh.

SMK PGRI Tanjung Raja merupakan sekolah yang terletak di Jalan Sultan Mahmud Badaruddin 2, Tanjung Raja Barat, Kecamatan Tanjung Raja, Kabupaten Ogan Ilir. Kondisi sekolah ini berada di daerah kondisi jalan yang datar, karenanya sangatlah mudah untuk dijangkau untuk menuju ke sekolah baik itu ditempuh dengan berjalan kaki, bersepeda ataupun kendaraan roda empat. Namun dilihat dari keseharian peserta didik SMK PGRI Tanjung Raja, saat berangkat maupun pulang sekolah sebagian banyak mengendarai kendaraan bermotor. Dengan keadaan ini dimungkinkan banyak peserta didik yang tidak bugar. Peserta didik kurang gerak dan kurang kegiatan fisik, sehingga tidak bisa tampil optimal dalam mengisi kegiatan sehari-hari mulai dari kegiatan di sekolah hingga selesai bahkan sampai kegiatan di rumah. Sehingga harapan dan tujuan pembelajaran untuk mendapatkan hasil yang baik menjadi tidak tercapai secara penuh seperti yang diharapkan.

Upaya yang dilakukan SMK PGRI Tanjung Raja dalam meningkatkan kesegaran jasmani peserta didik selain melakukan pembelajaran Pendidikan Jasmani, Olahraga dan Kesehatan (Penjas Orkes) adalah dengan melaksanakan berbagai program kegiatan ekstrakurikuler. Ekstrakurikuler merupakan kegiatan yang dilakukan di luar jam pelajaran yang bertujuan untuk memberikan fasilitas dalam mengembangkan potensi atau keterampilan peserta didik yang tidak tersalurkan pada saat pembelajaran di sekolah seperti di bidang olahraga, seni dan lainnya.

Kegiatan ekstrakurikuler merupakan salah satu upaya mengembangkan potensi peserta didik dan pembinaan yang diselenggarakan di lingkungan sekolah. Adanya kegiatan ini keterampilan peserta didik akan dilatih dengan berbagai bentuk latihan khusus sesuai cabang olahraga yang dipilih dan diminati para peserta didik, agar keterampilan olahraga di kalangan peserta didik akan terus meningkat dan mencapai hasil maksimal. Maka dari itu, kegiatan ekstrakurikuler ini harus berjalan sesuai dengan program latihan yang telah disusun dan nantinya diterapkan pada peserta didik. Adapun ekstrakurikuler yang diselenggarakan di SMK PGRI Tanjung Raja antara lain sepakbola, bola voli dan karatedo. Khusus ekstrakruikuler karatedo cukup diminati peserta didik, yaitu sebanyak 32 peserta didik. 
Karatedo merupakan olahraga beladiri yang tidak hanya menggunakan tangan tetapi juga menggunakan kaki dan bisa juga untuk menjaga diri. Tetapi, dalam pelaksanaannya tidak semua peserta ekstrakurikuler karatedo memiliki tingkat kebugaran jasmani yang cukup baik. Hal ini nampak dari kelelahan yang dialami peserta pada saat mengikuti latihan. Oleh karena itu, sebagai salah satu upaya untuk meningkatkan kesegaran jasmani peserta ekstrakurikuler karatedo adalah dengan menerapkan latihan maraton secara bertahap. Lari maraton adalah lari jarak jauh sepanjang $42,195 \mathrm{~km}$ yang dapat ditempuh sebagai lomba di jalan raya maupun luar jalan raya (offroad). Berdasarkan jarak yang ditempuh tersebut, diduga dapat mengembangkan komponenkomponen yang terdapat dalam kesegaran jasmani. Komponen-komponen kesegaran jasmani meliputi daya tahan kardiovaskuler, kekuatan otot, daya tahan otot, fleksibilitas, komposisi tubuh dan lain-lain. Oleh karena itu, sebagai salah satu upaya untuk menindaklanjuti permasalahan tersebut, yaitu dengan mengadakan penelitian yang berjudul: "Pengaruh Latihan Maraton Jarak Bertahap Terhadap Tingkat Kesegaran Jasmani Siswa Putra Ekstrakurikuler Karatedo SMK PGRI Tanjung Raja.” Penelitian ini bertujuan untuk mengetahui mengetahui pengaruh latihan maraton jarak bertahap terhadap tingkat kesegaran jasmani siswa putra ekstrakurikuler karatedo SMK PGRI Tanjung Raja

Kesegaran jasmani adalah kebugaran fisik (physical fitness) yakni kemampuan seseorang melakukan kerja sehari-hari secara efisien tanpa timbul kelelahan yang berlebihan sehingga masih dapat menikmati waktu luangnya (Irianto, 2006: 2). Pengertian kesegaran jasmani menurut Afriwardi (2011: 37) adalah suatu keadaan ketika tubuh masih memiliki sisa tenaga untuk melakukan kegiatan-kegiatan ringan yang bersifat rekreasi atau hiburan setelah melakukan kegiatan atau aktivitas fisik rutin.

Kurniawan (2011: 121) menyatakan bahwa, karatedo adalah seni bela diri yang berasal dari Jepang. Seni bela diri karate dibawa masuk ke Jepang lewat Okinawa. Seni bela diri ini pertama kali disebut "Tote" yang berarti seperti "Tangan China". Okinawa adalah suatu wilayah berbentuk kerajaan yang bebas merdeka. Pada waktu itu Okinawa mengadakan hubungan dagang dengan pulau-pulau tetangga. Salah satu pulau tetangga yang menjalin hubungan kuat adalah Cina. Hasilnya Okinawa mendapatkan pengaruh yang kuat akan budaya Cina. Menurut Mukhsin (2003: 13), karatedo adalah seni perkasa untuk pembinaan kepribadian melalui latihan sehingga karateka dapat mengatasi segala rintangan, nyata ataupun tidak nyata. Karatedo sesungguhnya merupakan seni bela diri tangan kosong di mana tangan dan kaki dilatih sedemikian rupa secara sistematis sehingga serangan tiba-tiba dari musuh dapat dikendalikan dengan menampilkan suatu kekuatan, tidak ubahnya seperti menggunakan senjata. Sedangkan menurut Midgley (2005: 62), karatedo adalah permainan praktis teknik pertandingan tangan kosong, metode formil untuk melatih fisik, mental dan olahraga yang penuh persaingan.

Maraton secara bertahap adalah jenis latihan berlari menempuh jarak 42,195 km. Latihan ini dilakukan secara bertahap dengan jarak 5.000 meter, 6.000 meter, 7.000 meter sampai 10.000 meter. Berdasarkan jarak tempuh tersebut, diidentifikasikan bahwa dengan latihan maraton jarak bertahap dapat meningkatkan kesegaran jasmani peserta ekstrakurikuler karatedo. Jelasnya kerangka berfikir dalam penelitian ini dapat dilihat pada diagram berikut.

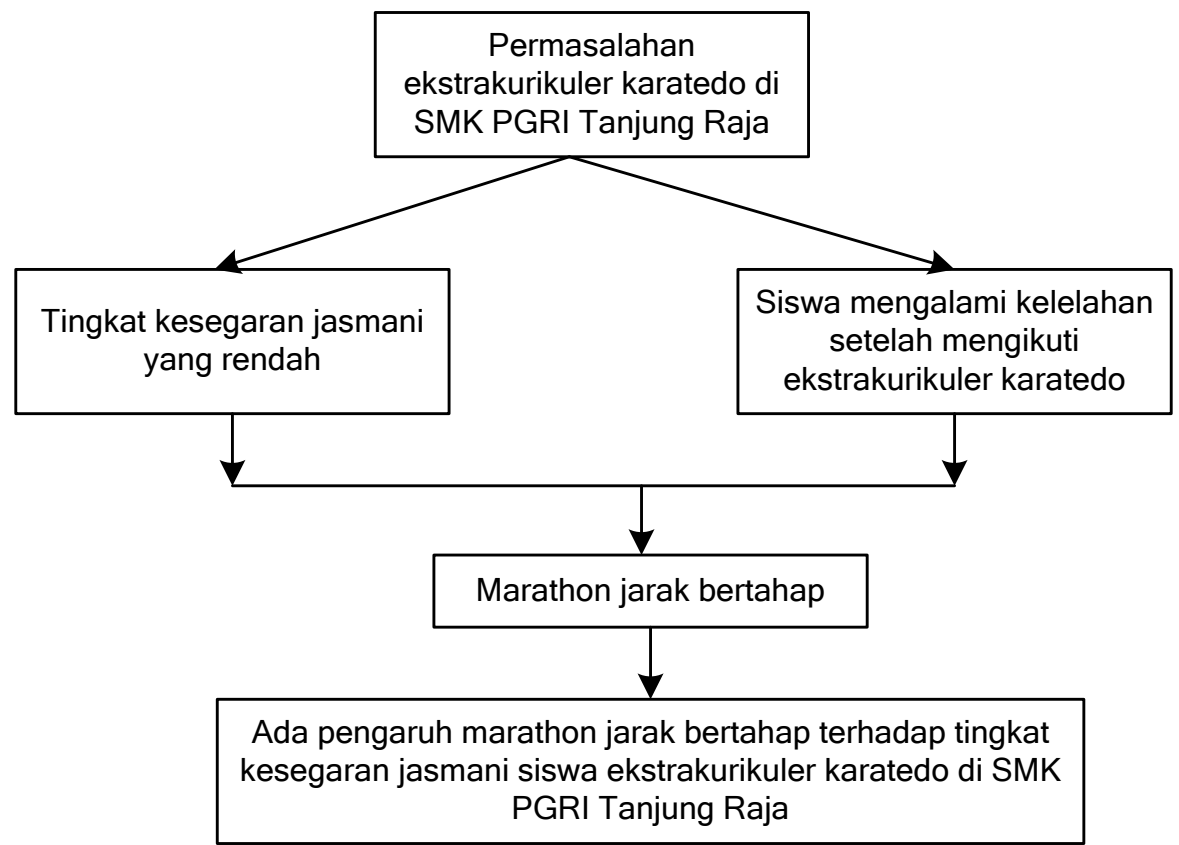

Gambar 1. Kerangka Berpikir

(Sumber: Syarifudin, 2018)

Dipublikasikan Oleh : 


\section{METODE PENELITIAN}

Penelitian ini dilihat dari jenisnya termasuk penelitian kuantitatif. Rancangan penelitian berupa eksperimen one design group pretest-posttest. Menurut Sugiyono (2011:75) bahwa design group pretest-posttest merupakan desain yang memberikan pretest sebelum diberikan perlakuan. Dengan demikian hasil perlakuan dapat diketahui lebih akurat, karena dapat membandingkan dengan keadaan sebelum diberi perlakuan.

Dalam penelitian ini terdapat dua variabel, yaitu latihan maraton dengan jarak bertahap sebagai variabel bebas, dan kesegaran jasmani (Y) sebagai variabel terikat. Populasi dalam penelitian ini adalah siswa putra ekstrakurikuler karatedo di SMK PGRI Tanjung Raja dengan jumlah populasi sebanyak 32 orang, sedangkan sampel diambil sama dengan jumlah populasi. Instrumen penelitian yang digunakan adalah tes TKJI yang meliputi: lari 60 meter (usia 16-19 tahun), gantung angkat tubuh untuk putra (pull up), baring duduk (sit up), loncat tegak (vertical jump), dan lari 1200 meter (usia 16-19 tahun).

Hipotesis yang diajukan dalam penelitian ini, yaitu:

1. $\mathrm{H}_{0}$ : Tidak ada pengaruh latihan maraton jarak bertahap terhadap tingkat kesegaran jasmani siswa putra ekstrakurikuler karatedo SMK PGRI Tanjung Raja

2. $\mathrm{H}_{\mathrm{a}}$ : Ada pengaruh latihan maraton jarak bertahap terhadap tingkat kesegaran jasmani siswa putra ekstrakurikuler karatedo SMK PGRI Tanjung Raja

Menurut Sugiyono (2011:147) bahwa dalam penelitian kuantitatif, analisis data merupakan kegiatan setelah data dari seluruh responden atau sumber data lain terkumpul. Analisis data dalam penelitian ini adalah sebagai berikut:

1. Uji Normalitas

Uji normalitas dilakukan sebagai bahan pertimbangan yang digunakan untuk menguji menguji hipotesis (Sugiyono, 2011: 172). Uji normalitas bertujuan untuk mengetahui distribusi data dalam variabel yang akan digunakan dalam penelitian. Data yang baik dan layak adalah data yang memiliki distribusi normal. Uji normalitas dalam penelitian ini menggunakan uji Liliefors, dengan rumus.

$$
\mathrm{z}=\frac{\mathrm{x}_{1}-\overline{\mathrm{X}}}{\mathrm{s}}
$$

Keterangan:

$\mathrm{x}_{\mathrm{i}}=$ data hasil tes

$\overline{\mathrm{X}}=$ rata-rata

$\mathrm{s}=$ simpangan baku

2. Uji Homogenitas

Uji homogenitas digunakan untuk mengetahui apakah beberapa varians populasi memiliki kesamaan atau tidak. Uji ini dilakukan sebagai prasyarat dalam uji-t. Pengujian homogenitas sampel pada penelitian ini digunakan uji Bartleth dengan rumus:

$$
\chi^{2}=\ln 10\left\{\left(\beta-\sum\left(\mathrm{n}_{\mathrm{i}}-1\right)\right) \log \mathrm{S}_{\mathrm{i}}^{2}\right.
$$

Dengan $\ln 10=2,3026$ disebut logaritma asli dari bilangan 10 . Menentukan $\chi_{\text {tabel }}^{2}$ dengan taraf signifikansi $(\alpha) 5 \%$, didapat dari daftar distribusi chi-kuadrat dengan peluang $(1-\alpha)$ dan $\mathrm{dk}=(\mathrm{k}-1)$ diperoleh $\chi_{\text {tabel }}^{2}=3,84$. Kriteria pengujian homogenitas sebagai berikut:
a. Jika $: \chi^{2}$ hitung $\geq \chi^{2}$ tabel berarti tidak homogen

b. Jika $: \chi^{2}$ hitung $<\chi^{2}$ tabel berarti homogen

3. Uji Hipotesis berikut.

Teknik pengujian hipotesis dalam penelitian ini menggunakan statistik uji t dengan rumus sebagai

$$
\mathrm{t}=\frac{\mathrm{Md}}{\sqrt{\frac{\sum \mathrm{X}^{2} \mathrm{~d}}{\mathrm{~N}(\mathrm{~N}-1)}}}(\text { Arikunto, 2010: 309) }
$$

Keterangan:

$\mathrm{Md}=$ mean dari perbedaan pretest dengan posttest (posttest - pretest)

$\mathrm{xd}=$ standar deviasi selisih pengukuran 1 dan 2

$\sum \mathrm{x}^{2} \mathrm{~d}=$ jumlah kuadrat deviasi

$\mathrm{N} \quad=$ jumlah sampel

d.b $=$ ditentukan $\mathrm{N}-1$

Dipublikasikan Oleh :

UPT Publikasi dan Pengelolaan Jurnal

Universitas Islam Kalimantan Muhammad Arsyad Al-Banjari Banjarmasin 


\section{HASIL DAN PEMBAHASAN}

Deskripsi data pretest dan posttest tingkat kesegaran jasmani siswa dapat dilihat pada tabel berikut.

Tabel 1.

Deskripsi Data Kesegaran Jasmani Siswa

\begin{tabular}{cccccc}
\hline \multirow{2}{*}{ No } & \multirow{2}{*}{ Jumlah Nilai } & \multicolumn{2}{c}{ Pretest } & \multicolumn{2}{c}{ Posttest } \\
\cline { 2 - 6 } & & $\sum$ & \% & $\sum$ & \% \\
\hline 1 & $22-25$ & 0 & 0.00 & 0 & 0.00 \\
\hline 2 & $18-21$ & 0 & 0.00 & 0 & 0.00 \\
\hline 3 & $14-17$ & 2 & 6.25 & 21 & 65.63 \\
\hline 4 & $10-13$ & 16 & 50.00 & 10 & 31.25 \\
\hline 5 & $5-9$ & 14 & 43.75 & 1 & 3.13 \\
\hline & Jumlah & $\mathbf{3 2}$ & $\mathbf{1 0 0 . 0 0}$ & $\mathbf{3 2}$ & $\mathbf{1 0 0 . 0 0}$ \\
\hline
\end{tabular}

Tabel 1 di atas menyatakan bahwa hasil pretest tingkat kesegaran jasmani pada jumlah nilai $14-17$ dengan kategori sedang sebanyak 2 orang (6,25\%), hal ini meningkat pada posttest menjadi 21 orang $(65,63 \%)$, terdapat 16 orang $(50,00 \%)$ mendapatkan jumlah nilai $14-17$ dengan kategori kurang, hal ini menurun pada hasil posttest menjadi 10 orang $(31,25 \%)$, dan terdapat 14 orang $(43,75 \%)$ mendapatkan nilai $5-9$ dengan kategori kurang sekali, hal ini juga menurun menjadi 1 orang $(3,13 \%)$. Secara keseluruhan tingkat kesegaran jasmani mengalami peningkatan dari kategori kurang menjadi sedang

Uji normalitas data merupakan syarat yang harus dipenuhi sebelum pengujian hipotesis dilakukan. Uji normalitas dalam penelitian ini menggunakan uji Liliefors, yang hasilnya dapat dilihat pada tabel berikut.

\section{Tabel 2.}

Hasil Pengujian Normalitas Data

\begin{tabular}{ccccc}
\hline No & Data & L $_{0}$ & L $_{\text {tabel }}$ & Keterangan \\
\hline 1 & Pretest & 0,1560 & \multirow{2}{*}{0,1566} & Normal \\
\cline { 1 - 3 } \cline { 5 - 6 } & Posttest & 0,0909 & & Normal \\
\hline
\end{tabular}

Tabel 2 di atas, menunjukkan bahwa hasil pengujian normalitas didapat nilai $\mathrm{L}_{\mathrm{o}}<\mathrm{L}_{\text {tabel }}$, maka $\mathrm{H}_{\mathrm{o}}$ diterima dan disimpulkan data pretest dan posttest kesegaran jasmani siswa berdistribusi normal.

Pengujian homogenitas digunakan untuk melihat apakah kedua data mempunyai varians yang homogen atau tidak. Peneliti dalam hal ini menggunakan uji Bartlett dengan rumus $\chi^{2}=\ln 10\left\{\left(\beta-\sum\left(\mathrm{n}_{\mathrm{i}}-1\right)\right) \log \mathrm{S}_{\mathrm{i}}^{2}\right.$. Untuk mempermudah perhitungan homogenitas data digunakan tabel berikut.

Tabel 3.

Pengujian Homogenitas Data

\begin{tabular}{cccccc}
\hline Data & $\mathbf{d k}=\mathbf{n} \mathbf{- 1}$ & $\mathbf{S i}^{\mathbf{2}}$ & $\mathbf{d k ~ \mathbf { ~ i } ^ { \mathbf { 2 } }}$ & $\mathbf{l o g} \mathbf{~ i}^{\mathbf{2}}$ & $\mathbf{d k} \mathbf{l o g s} \mathbf{~}^{\mathbf{2}}$ \\
\hline Pretest & $32-1=31$ & 4.65 & 144.15 & 0.6675 & 20.6910 \\
\hline Posttest & $32-1=31$ & 4.35 & 134.85 & 0.6385 & 19.7932 \\
\hline Jumlah & $\mathbf{6 2}$ & 9.00 & 279.00 & 1.3059 & 40.4842 \\
\hline
\end{tabular}

Langkah-langkah Uji Homogenistas

$$
\begin{aligned}
& \mathrm{S}_{\mathrm{i}}^{2}=\frac{\sum\left(\mathrm{n}_{\mathrm{i}}-1\right) \mathrm{S}^{2}}{\sum\left(\mathrm{n}_{\mathrm{i}}-1\right)} \\
& \mathrm{S}_{\mathrm{i}}^{2}=\frac{279,00}{62}=4,5
\end{aligned}
$$

Harga satuan $\beta$

$$
\beta=\log \mathrm{S}_{\mathrm{i}}^{2}\left(\mathrm{n}_{\mathrm{i}}-1\right)
$$

$\beta=\log (4,5) 62$

$\beta=0,6532 \times 62$

$\beta=40,4992$

Cari harga $\chi^{2}$

$\chi^{2}=\ln 10\left\{\left(\beta-\sum\left(\mathrm{n}_{\mathrm{i}}-1\right)\right) \log \mathrm{S}_{\mathrm{i}}^{2}\right.$

$=2,303(40,4992-40,4842)$

$=0,03$

Syarat homogen $\chi^{2}$ hitung $<\chi^{2}$ tabel dari perhitungan di atas diperoleh dari daftar Chi Kuadrat dengan $\mathrm{dk}=\mathrm{k}$ -1 dan $\alpha=0,05$ didapat 3,84. Ini berarti $\chi^{2}$ hitung $<\chi_{\text {tabel }}^{2}$ atau $0,03<3,84$, sehingga sampel tersebut homogen 
pada taraf 0,05 . Data dalam penelitian ini telah berdistribusi normal dan homogen, sehingga dapat dilanjutkan dengan pengujian hipotesis.

Setelah data dinyatakan berdistribusi normal dan homogen, maka selanjutnya dilakukan uji hipotesis dengan menggunakan uji-t.

Harga Md dan $\mathrm{X}^{2} \mathrm{~d}$ diperoleh dengan menggunakan rumus:

$$
\begin{aligned}
& \mathrm{Md}=\frac{\sum \mathrm{d}}{\mathrm{N}} \\
& \mathrm{Md}=\frac{146}{32}=4,5625
\end{aligned}
$$

Setelah diperoleh selisih (Md) tes awal (pretest) dan tes akhir (posttest) tingkat kesegaran jasmani siswa putra ekstrakurikuler karatedo SMK PGRI Tanjung Raja, maka langkah selanjutnya dilakukan perhitungan varians $\left(\sum \mathrm{X}^{2} \mathrm{~d}\right)$ menggunakan rumus sebagai berikut.

$$
\begin{aligned}
& \sum X^{2} d=\sum d^{2}-\frac{\left(\sum d\right)^{2}}{N} \\
& \sum X^{2} d=702-\frac{(146)^{2}}{32} \\
& \sum X^{2} d=35,8750
\end{aligned}
$$

Harga Md dan $\sum \mathrm{X}^{2} \mathrm{~d}$ yang diperoleh disubsitusikan ke dalam rumus uji t sebagai berikut.

$$
\begin{aligned}
& t=\frac{M d}{\sqrt{\frac{\sum X^{2} d}{N(N-1)}}} \\
& t=\frac{4,5625}{\sqrt{\frac{35,8750}{32(32-1)}}} \\
& t=\frac{4,5625}{\sqrt{\frac{35,8750}{992}}} \\
& t=\frac{4,5625}{\sqrt{0,036164}} \\
& t=\frac{4,5625}{0,190169} \\
& t=23,99
\end{aligned}
$$

Setelah $t_{\text {hitung }}$ diketahui selanjutnya menginterpretasikan ke tabel " $\mathrm{t}$ " dengan $\mathrm{dk}=32-1$, dan peluang ( 1 - $\alpha$ ), dimana $\alpha=0,05$. Sehingga $t_{\text {tabel }}$ diperoleh 1,697. Dengan demikian, dapat dinyatakan bahwa $t_{\text {hitung }}>t_{\text {tabel }}$ atau 23,99 >1,697, maka tolak $\mathrm{H}_{\mathrm{o}}$ dan terima $\mathrm{H}_{\mathrm{a}}$, berarti hipotesis yang berbunyi ada pengaruh latihan maraton jarak bertahap terhadap tingkat kesegaran jasmani siswa putra ekstrakurikuler karatedo SMK PGRI Tanjung Raja diterima kebenarannya.

Berdasarkan analisis data yang telah diuraikan, dapat diketahui bahwa siswa putra ekstrakurikuler karatedo di SMK PGRI Tanjung Raja telah mengikuti program latihan maraton jarak bertahap dengan bersungguh-sungguh, dalam artian benar mengikuti latihan. Meskipun fisik menjadi prioritas utama mereka saat mengikuti latihan. Latihan maraton jarak bertahap dapat dilakukan dengan baik dan benar sesuai dengan arahan peneliti. Hal ini dapat dilihat dari aktivitas siswa sewaktu latihan dalam setiap pertemuan selalu serius mengikuti latihan yang diberikan. Latihan maraton jarak bertahap bertujuan untuk meningkatkan kebugaran jasmani siswa putra ekstrakurikuler karatedo SMK PGRI Tanjung Raja.

Berdasarkan hasil penelitian, didapat hasil pretest tingkat kesegaran jasmani yang diukur melalui lari 60 meter (usia 16-19 tahun), gantung angkat tubuh untuk putra (pull up), baring duduk (sit up), loncat tegak (vertical jump), dan lari 1200 meter (usia 16-19 tahun) dengan skor maksimum 15, skor minimum 5 dengan rentang (selisih) 10, dan rata-rata sebesar 9,75 (dibulatkan 10) yang terletak pada interval 10 - 13 (Nurhasan, 2008:6.31) dikategorikan kurang. Setelah diketahui tingkat awal kesegaran jasmani siswa, selanjutnya siswa 
diberikan latihan maraton jarak bertahap sebanyak 18 kali pertemuan. Akhir dari penelitian adalah melaksanakan posttest tingkat kesegaran jasmani.

Hasil posttest tingkat kesegaran jasmani siswa diperoleh skor maksimum 18, skor minimum 9 dengan rentang (selisih) 9, dan rata-rata 14,31 (dibulatkan 14). Rata-rata ini terletak apda interval 14 - 17 (Nurhasan, 2008) dikategorikan sedang. Dengan demikian, pencapaian ini menunjukkan adanya peningkatan sebesar 4,56.

Setelah data pretest dan postest didapat maka dilakukan uji normalitas dan uji homogenitas, setelah diuji data berdistribusi normal dan homogen. Selanjutnya dapat dilakukan pengujian hipotesis menggunakan statistik "uji $t$ ". Kriteria pengujian hipotesis terima Ho jika $t_{\text {hitung }}<t_{\text {tabel }(1-\alpha)}$ dan tolak Ho jika $t_{\text {hitung }}>t_{\text {tabel }(1-\alpha)}$ dimana $\mathrm{t}_{(1-\alpha)}$ didapat dari tabel distribusi $\mathrm{t}$ dengan $\mathrm{dk}=\mathrm{n}-1$, untuk $\mathrm{t}_{\text {hitung }}=23,99$, sedangkan untuk $\mathrm{t}_{\text {tabel }}=1,697$, jadi $t_{\text {hitung }}>t_{t a b e l}$ atau 23,99 $>1,697$. Dengan demikian, ada pengaruh yang signifikan latihan maraton jarak bertahap terhadap tingkat kesegaran jasmani siswa putra ekstrakurikuler karatedo SMK PGRI Tanjung Raja. Adanya pengaruh tersebut selaras dengan pendapat Sukirno (2017) bahwa pada hakikatnya yang dimaksud dengan latihan adalah suatu kegiatan atau aktivitas fisik untuk meningkatkan kualitas atau kemampuan fisik (jasmani) seseorang dalam menghadapi suatu kegiatan.

Hal ini juga dapat diketahui melalui hasil penelitian yang menunjukkan bahwa latihan maraton jarak bertahap memberikan kontribusi terhadap tingkat kesegaran jasmani siswa. Peningkatan ini juga menunjukkan bahwa latihan maraton jarak bertahap dapat digunakan sebagai alternatif untuk meningkatkan tingkat kesegaran jasmani siswa.

\section{PENUTUP}

\section{Kesimpulan}

Berdasarkan analisa data hasil penelitian dapat disimpulkan bahwa latihan maraton jarak bertahap berpengaruh secara signifikan terhadap tingkat kesegaran jasmani siswa putra ekstrakurikuler karatedo SMK PGRI Tanjung Raja.

\section{Saran}

1. Bagi guru dan pelatih, bahwa penelitian ini dapat dijadikan bahan/materi rujukan untuk meningkatkan kesegaran jasmani peserta didiknya.

2. Perlu penelitian lanjutan agar memperoleh gambaran yang komprehensif dalam meningkatkan kesegaran jasmani seseorang, salah satunya dengan memperbanyak sampel dan variabel yg lebih luas lagi.

\section{REFERENSI}

Afriwardi. 2011. Ilmu Kedokteran Olahraga. Jakarta: EGC Kedokteran.

Arikunto, Suharsimi. 2010. Prosedur Penelitian Suatu Pendekatan Praktik. Jakarta: Rineka Cipta.

Kurniawan, Feri. 2011. Buku Pintar Olahraga. Jakarta: Laskar Aksara.

Irianto, Djoko Pekik. 2006. Bugar \& Sehat Dengan Berolahraga. Yogyakarta: Andi.

Midgley, Rud. 2005. Ensiklopedi Olahraga. Semarang: Dahara Prize.

Mukhsin, Sabeth. 2003. Karate Tradisional. Jakarta: PT Gramedia.

Sugiyono. 2011. Metode Penelitian Pendidikan Pendekatan Kuantitaif, Kualitatif R\&D. Bandung: Alfabeta.

Sumaryoto dan Nopembri, Soni. 2016. Pendidikan Jasmani, Olahraga dan Kesehatan SMA/MA Kelas XI. Jakarta: Kemendikbud. 